\title{
Niche Recycling through Division-Independent Egress of Hematopoietic Stem Cells
}

\section{Citation}

Bhattacharya, Deepta, Agnieszka Czechowicz, A. G. Lisa Ooi, Derrick J. Rossi, David Bryder, and Irving L. Weissman. 2009. Niche recycling through division-independent egress of hematopoietic stem cells. The Journal of Experimental Medicine 206(12): 2837-2850.

\section{Published Version}

doi:10.1084/jem.20090778

\section{Permanent link}

http://nrs.harvard.edu/urn-3:HUL.InstRepos:4744852

\section{Terms of Use}

This article was downloaded from Harvard University's DASH repository, and is made available under the terms and conditions applicable to Other Posted Material, as set forth at http:// nrs.harvard.edu/urn-3:HUL.InstRepos:dash.current.terms-of-use\#LAA

\section{Share Your Story}

The Harvard community has made this article openly available.

Please share how this access benefits you. Submit a story.

\section{Accessibility}




\title{
Niche recycling through division- independent egress of hematopoietic stem cells
}

\author{
Deepta Bhattacharya, ${ }^{1}$ Agnieszka Czechowicz, ${ }^{1}$ A.G. Lisa Ooi, ${ }^{1}$ \\ Derrick J. Rossi, ${ }^{2}$ David Bryder, ${ }^{3}$ and Irving L. Weissman ${ }^{1}$
}

IInstitute of Stem Cell Biology and Regenerative Medicine Stanford University School of Medicine Stanford, CA 94305 ${ }^{2}$ Immune Disease Institute, Harvard Stem Cell Institute Department of Pathology, Harvard Medical School Boston, MA 02115

${ }^{3}$ Immunology Unit Institution for Experimental Medical Science Lund University, BMC 113, 22184 Lund, Sweden

Hematopoietic stem cells (HSCs) are thought to reside in discrete niches through stable adhesion, yet previous studies have suggested that host HSCs can be replaced by transplanted donor HSCs, even in the absence of cytoreductive conditioning. To explain this apparent paradox, we calculated, through cell surface phenotyping and transplantation of unfractionated blood, that $\sim 1-5 \%$ of the total pool of HSCs enters into the circulation each day. Bromodeoxyuridine (BrdU) feeding experiments demonstrated that HSCs in the peripheral blood incorporate $\mathrm{BrdU}$ at the same rate as do HSCs in the bone marrow, suggesting that egress from the bone marrow to the blood can occur without cell division and can leave behind vacant HSC niches. Consistent with this, repetitive daily transplantations of small numbers of HSCs administered as new niches became available over the course of $7 \mathrm{~d}$ led to significantly higher levels of engraftment than did large, single-bolus transplantations of the same total number of HSCs. These data provide insight as to how HSC replacement can occur despite the residence of endogenous HSCs in niches, and suggest therapeutic interventions that capitalize upon physiological HSC egress.

\section{CORRESPONDENCE}

Deepta Bhattacharya:

deeptab@wustl.edu

Abbreviations used: EPO, erythropoietin; G-CSF, granulocyte colony stimulating factor; HSC, hematopoietic stem cell; $\mathrm{KLS}, \mathrm{c}-\mathrm{kit}^{+}$lineage- $\mathrm{Sca}-1^{+}$; $\mathrm{M}-\mathrm{CSF}$, macrophage colony stimulating factor; $\mathrm{MP}$, myeloid progenitor; MPP, multipotent progenitor; SCF, stem cell factor; TPO, thrombopoietin.
The concept that hematopoietic stem cell (HSC) numbers and behavior are regulated by physically discrete locations or niches within the bone marrow was first hypothesized in detail $30 \mathrm{yr}$ ago (Schofield, 1978). In recent years, several groups have begun to reveal the identity of the HSC niche, either through in situ identification of populations enriched for HSCs in mouse bone marrow or through genetic approaches (Nilsson et al., 1997; Calvi et al., 2003; Zhang et al., 2003; Arai et al., 2004; Visnjic et al., 2004; Kiel et al., 2005; Sugiyama et al., 2006). Although the precise identities of the niche cells are still largely unknown and controversial (Kiel et al., 2007a; Haug et al., 2008), a large amount of data indicate that HSCs are retained within the niche through the use of specific adhesion molecules and chemokine gradients (Papayannopoulou and Scadden, 2008).

$\overline{\text { D. Bhattacharya and A. Czechowicz contributed equally to }}$ this paper.

D. Bhattacharya's present address is Dept. of Pathology and Immunology, Washington University School of Medicine, St. Louis, MO 63110.
Through these interactions, HSCs can be assured of receiving the appropriate supportive signals that allow them to retain their stem cell identity.

Counterbalanced against these studies, however, are data suggesting that recipient bone marrow can be readily displaced by transplanted marrow in an efficient and linear dose-dependent manner, even in the absence of conditioning (Brecher et al., 1982; Saxe et al., 1984; Stewart et al., 1993; Wu and Keating, 1993; Rao et al., 1997; Colvin et al., 2004). These studies did not directly assess HSC replacement; however, the data would appear to be more consistent with a model where HSCs do not reside locked into fixed locations in the marrow, but instead receive their regulatory signals through limiting quantities of freely diffusible factors. Although more recent data have shown that actual host HSC replacement by purified

Q 2009 Bhattacharya et al. This article is distributed under the terms of an Attribution-Noncommercial-Share Alike-No Mirror Sites license for the first six Attribution-Noncommercial-Share Alike-No Mirror Sites license for the first six
months after the publication date (see http://www.jem.org/misc/terms.shtml). After six months it is available under a Creative Commons License (Attribution-Noncommercial-Share Alike 3.0 Unported license, as described at http://creativecommons .org/licenses/by-nc-sa/3.0/). 
HSCs, rather than simply total marrow replacement, is less efficient than these earlier studies suggested (Prockop and Petrie, 2004; Bhattacharya et al., 2006; Czechowicz et al., 2007), there is clearly a certain degree of HSC replacement that does occur in normal mice, even in the absence of cytoreductive conditioning. Thus, there is a need for a model that accounts for both the physically discrete bone marrow locations of HSCs that many studies have suggested, and the replacement of HSCs that occurs when transplants are performed in the absence of conditioning.

Recent studies have shown that pharmacologically induced egress of HSCs using AMD3100, a CXCR4 inhibitor, can be used to free niches in recipient animals and allows for improved levels of donor HSC engraftment relative to untreated recipients (Chen et al., 2006). Because several studies have shown that HSCs and/or progenitors also circulate under physiological conditions (Goodman and Hodgson, 1962; McCredie et al., 1971; Wright et al., 2001; Abkowitz et al., 2003; McKinney-Freeman and Goodell, 2004; Massberg et al., 2007; Méndez-Ferrer et al., 2008), we hypothesized that steady-state egress of HSCs from their niches may also allow for engraftment of donor HSCs. In this model, transplanted HSCs would not directly displace host HSCs that are stably residing within a niche, but would engraft into niches that had been vacated through the physiological egress of host HSCs. In this study, we provide evidence consistent with this model, demonstrating that HSCs can enter into the bloodstream in the absence of cellular division, and that repetitive HSC transplantations can capitalize on this process of HSC niche recycling to generate higher levels of engraftment than large single-bolus transplantation of HSCs. Moreover, in our study we specifically examined in an unconditioned setting the intrinsic behavior and replacement properties of HSCs rather than that of unfractionated bone marrow, which contains several different cell types that have been reported to influence engraftment and replacement, such as host-reactive T cells and stromal cells (Slavin et al., 1998; Almeida-Porada et al., 1999; Lazarus et al., 2005). To our knowledge, ours is the first such study to examine the physiological kinetics of HSC niche emptying and engraftment behavior in the absence of these variables.

\section{RESULTS}

\section{Numerical and functional quantification of HSCs in blood}

Several theoretical mechanisms exist that could describe the source of HSCs in the blood. The first involves an asymmetric division in which after mitosis, one daughter HSC remains positioned within the supportive niche, while the other daughter cell is displaced away (Fig. 1 A). The daughter cell that is displaced can then intravasate into the bloodstream. Another mechanism involves division-independent egress in which an HSC exits its supportive niche in the absence of mitosis, thus leaving behind a vacant HSC niche (Fig. $1 \mathrm{~B}$ ).

To determine which of these two models most accurately describes the source of HSCs in the peripheral blood, we first determined whether HSCs in the bloodstream are phenotypically and functionally similar to HSCs in the bone marrow. ${\mathrm{C}-\mathrm{kit}^{+} \text {lineage }}^{-} \mathrm{Sca}^{+}{ }^{+}$(KLS) CD27 ${ }^{+} \mathrm{IL}-7 \mathrm{R} \alpha^{-} \mathrm{CD} 150^{+} \mathrm{CD} 34^{-}$ cells could be identified by flow cytometry in the blood that appeared to be virtually identical to phenotypic HSCs in the bone marrow (Fig. 2 A). In agreement with some previous studies (Allman et al., 2003), but in contrast to others (Wiesmann et al., 2000), we were unable to identify KLS CD34- ${ }^{-}$cells in the bone marrow that did not express CD27, although it is
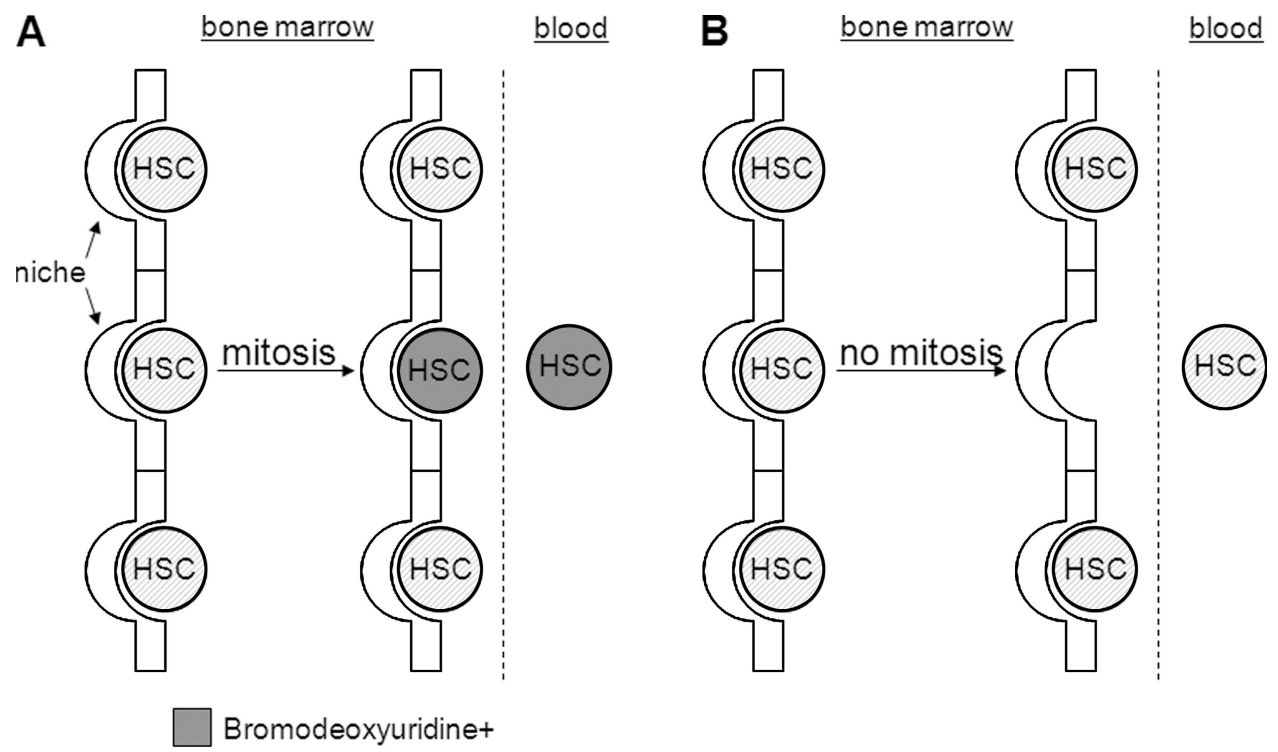

Figure 1. HSC egress is either division dependent or independent. HSCs can either undergo an extrinsically asymmetric division, in which one daughter cell is positioned away from a supportive niche and can thus intravasate to the blood (A) or can exit the supportive niche in the absence of cellular division (B). In the former model, all HSCs in the blood would be expected to have incorporated BrdU (gray shaded cells) after an appropriate feeding period, while the latter model would predict similar low BrdU incorporation rates between bone marrow and blood HSCs. 
worth noting that CD $34^{-}$HSCs express slightly lower relative levels of CD27 than do their CD34+ MPP counterparts (Fig. 2 B). We believe these discrepancies are related to improved antibody conjugates that yield brighter fluorescent signals. This marker thus aided in the specific identification of rare HSCs in the blood and distinguishing these HSCs from background CD27 ${ }^{-}$events (Fig. 2 B). Transplantation of CD27bone marrow did not lead to multilineage reconstitution beyond $8 \mathrm{wk}$, confirming that all of the HSC activity is contained within the $\mathrm{CD} 27^{+}$fraction (Fig. S1 A).

Previous studies have shown that functional HSC activity is contained within the KLS fraction of peripheral blood (Schwarz and Bhandoola, 2004). We further confirmed through transplantation assays that only CD $27^{+}$KLS cells within the peripheral blood have multilineage reconstitution potential (Fig. S1 B). To verify that HSC activity was specifically contained within the KLS CD27 ${ }^{+} \mathrm{IL}_{-} 7 \mathrm{R} \alpha^{-} \mathrm{CD} 150^{+} \mathrm{CD} 34^{-}$ fraction, we transplanted both $\mathrm{KLS} \mathrm{CD} 7^{+} \mathrm{IL}-7 \mathrm{R} \alpha^{-} \mathrm{CD} 150^{+}$
$\mathrm{CD}^{-} 4^{-}$and all remaining $\mathrm{KLS} \mathrm{CD}_{2} 7^{+} \mathrm{IL}-7 \mathrm{R} \alpha^{-}\left(\mathrm{CD} 34^{+}\right.$ and/or $\mathrm{CD} 150^{-}$) cells from peripheral blood into lethally irradiated recipients along with 200,000 competitor bone marrow cells from $\mathrm{GFP}^{+}$wild-type donor mice. Transplantation of as

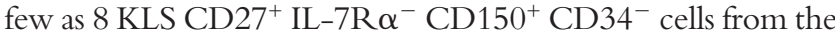
peripheral blood into lethally irradiated mice led to multilineage reconstitution for at least $16 \mathrm{wk}$, whereas transplantation of as many as 200 of the remaining KLS CD $27^{+} \mathrm{IL}-7 \mathrm{R} \alpha^{-}$cells (encompassing both $\mathrm{CD}^{+} 4^{+}$and/or $\mathrm{CD} 150^{-}$cells) from the peripheral blood failed to give detectable reconstitution at late time points in any recipient (Fig. $3 \mathrm{~A}$ ), similar to previous studies on bone marrow HSCs (Osawa et al., 1996). These data demonstrate that HSC activity in the peripheral blood is contained within the KLS CD27 ${ }^{+} \mathrm{IL}-7 \mathrm{R} \alpha^{-} \mathrm{CD} 150^{+} \mathrm{CD} 34^{-}$ population, just as in the bone marrow. To our knowledge, this is the first time that peripheral blood HSCs have been purified to this level, affording us the ability to specifically study their behavior.
A

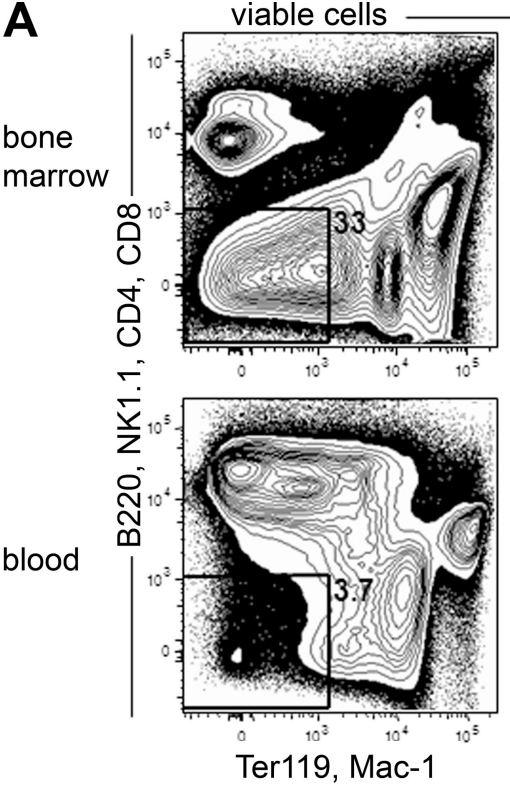

B

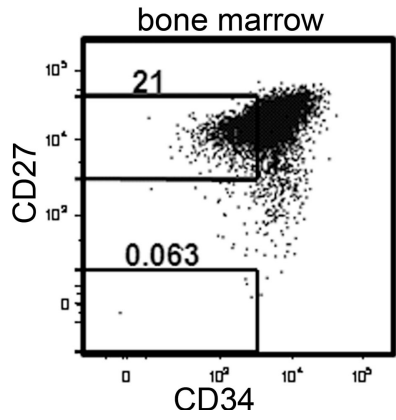

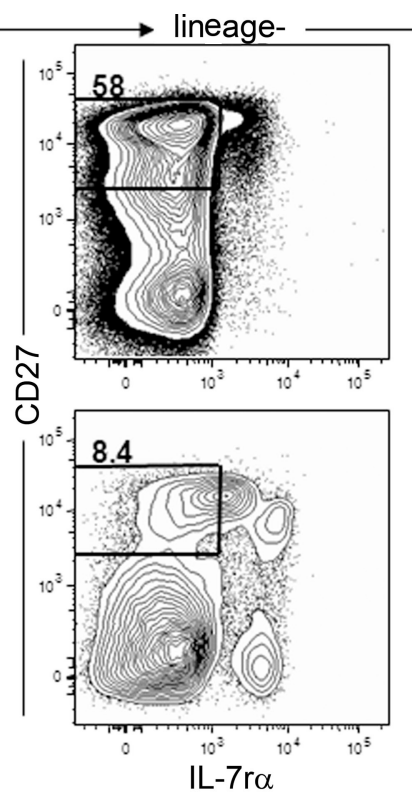

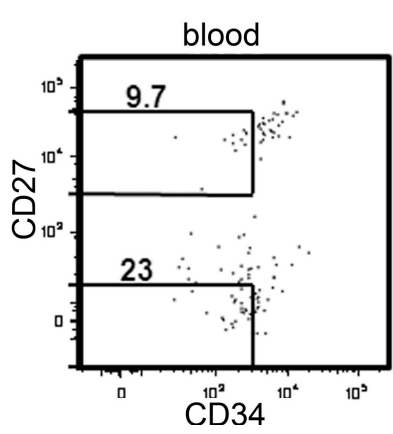

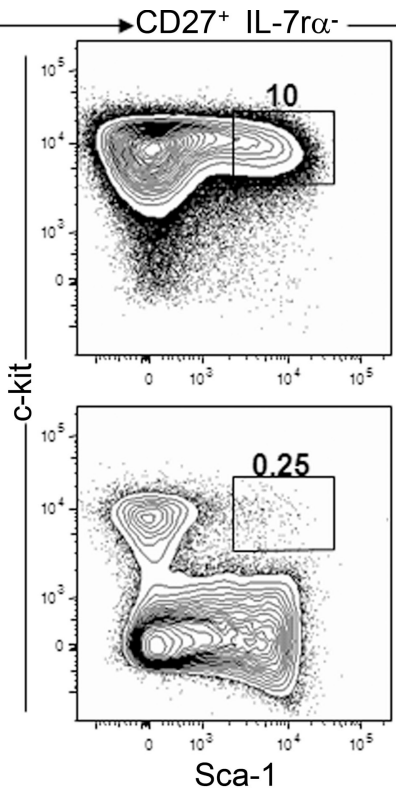

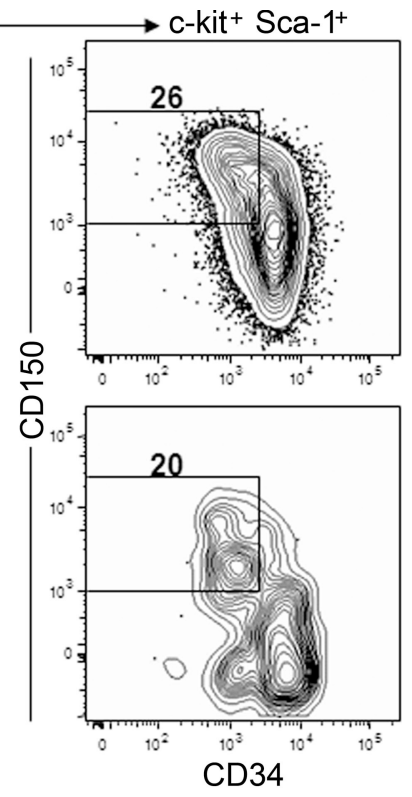

Figure 2. Phenotypic HSCs can be identified and purely isolated from peripheral blood. (A) Bone marrow and peripheral blood from 12-wk-old mice were stained with the combination of markers indicated. The plots from the peripheral blood represent pooled events collected from 25 animals, in which $\sim 50 \mathrm{HSCs}$ were analyzed. Lineage cocktail antibodies were divided into different channels to minimize the chance of contamination of mature cells in the HSC gate. (B) CD27 is expressed on HSCs. KLS IL-7r $\alpha^{-}$cells from the bone marrow and blood were examined for CD34 and CD27 expression. CD34- cells segregated almost exclusively to the $\mathrm{CD} 27^{+}$population in the bone marrow, and thus the CD27 marker was useful for distinguishing HSCs from background events in the blood. All stains were repeated in eight independent experiments. 
When 8 KLS CD27 ${ }^{+}$IL-7R $\alpha^{-} \mathrm{CD} 150^{+} \mathrm{CD}^{-} 4^{-}$(PB HSCs) were transplanted alongside 200,000 competitor bone marrow cells into lethally irradiated recipients, the mean granulocyte chimerism arising from the peripheral blood HSCs was $\sim 23 \%$ (Fig. 3 A). This is similar to the expected chimerism value of $28 \%$ if these HSCs were functionally identical to the 20 estimated bone marrow HSCs that were cotransplanted within the competitor bone marrow, assuming a bone marrow HSC frequency of $0.01 \%$ (Bryder et al., 2006). However, the lymphoid chimerism derived from the peripheral blood HSCs was slightly lower, perhaps because of the persistence and homeostatic proliferation of mature lymphocytes included in the competitor bone marrow (Ron and Sprent, 1985; Förster and Rajewsky, 1990; Ernst et al., 1999; Goldrath and Bevan, 1999). Clonal in vitro assays in which 20 single peripheral blood HSCs and 20 single bone marrow HSCs isolated from 10 mice were analyzed for colony formation demonstrated that the plating efficiency and lineage potential of peripheral blood HSCs are similar to those of bone marrow HSCs (Fig. 3 B). Collectively, these data demonstrate that peripheral blood HSCs are phenotypically and functionally similar to bone marrow HSCs.

To reexamine the frequency of functional HSCs within the blood of adult mice, we transplanted $200 \mu \mathrm{l}$ of whole peripheral blood ( $~ 10 \%$ of the total blood volume of a mouse) from unmanipulated animals into lethally irradiated recipients alongside 200,000 competitor bone marrow cells. These experiments showed that whereas almost all recipients (30/34) showed clear lymphoid lineage chimerism, only 4/34 recipients showed detectable donor granulocyte reconstitution at 16 wk after transplant (Fig. S2 A), likely indicating the persistence and/or homeostatic proliferation of mature donor lymphocytes, but relatively infrequent HSC activity. Assuming single-cell reconstitution frequency ranges of $20-100 \%$ (Osawa et al., 1996; Wagers et al., 2002; Matsuzaki et al., 2004; Ema et al., 2005; Camargo et al., 2006), these data suggest that there are not $>1-5$ circulating HSCs in the peripheral blood of 10-12-wk-old animals at any given point. Consistent with this, we were only able to sort, on average, 2 HSCs per adult animal from the entirety of the peripheral blood (Fig. 2 A). These numbers are lower than our previous estimates for reasons that are not entirely clear (Wright et al., 2001). The difference does not appear to be caused by the use of younger animals in our previous studies, as peripheral blood from 4-wk-old mice reconstituted granulocytes at an identical efficiency (2/14 recipients), as did peripheral blood from 12-wk-old mice (2/14 recipients; Fig. S2 B). Recent studies have found that diverse stimuli, such as circadian rhythms, can influence the frequency of HSCs in the blood (Méndez-Ferrer et al., 2008). Although this particular stimulus is unlikely to account for all of the difference between our current study and the previous work, it is clear that environmental factors, many of which likely remain to be discovered, can influence the numbers of HSCs in the blood. It is entirely possible that some of these environmental factors were different between the current study and our previous
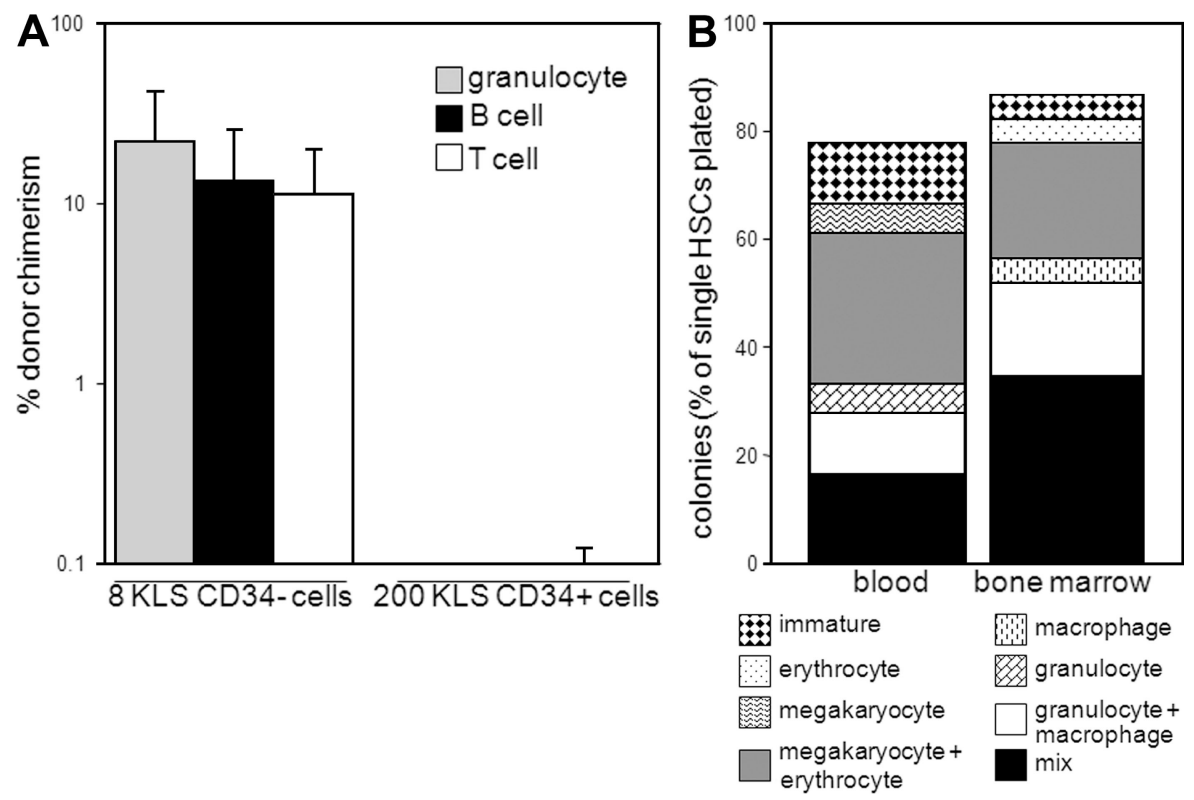

Figure 3. Functional HSCs can be found in the peripheral blood under physiological conditions. (A) Transplantable peripheral blood HSCs are contained within the CD34- fraction of CD27+ $\mathrm{KLS}$ cells. Either $8 \mathrm{KLSCD} 27^{+} \mathrm{CD} 150^{+} \mathrm{IL}-7 \mathrm{r} \alpha^{-} \mathrm{CD} 34^{-}$or 200 of the remaining $\mathrm{KLS} \mathrm{CD} 27^{+} \mathrm{IL}-7 \mathrm{r} \alpha^{-}$cells were transplanted into lethally irradiated recipients along with 200,000 competitor bone marrow cells and chimerism in various blood lineages was determined 16 wk after transplant. Means \pm SEM are shown ( $n=5$ for each group; experiment was repeated 3 times). (B) Clonal lineage potential of bone marrow and peripheral blood HSCs is similar. Single bone marrow or peripheral blood HSCs were cultured in the presence of SCF, Flt3L, IL-3, M-CSF, GM-CSF, TPO, and EPO for $12 \mathrm{~d}$, and the lineage composition of the colonies was determined through cytospins and May-Giemsa stains. 20 wells were analyzed for both peripheral blood and bone marrow HSCs. Two independent experiments were performed. 
work (Wright et al., 2001). Regardless, these current revised estimates are more consistent with data presented by other studies and with the observation that cross-engraftment of the bone marrow HSC compartment in parabiotic partners does not reach 50\%, even after long periods of conjoinment (Wright et al., 2001; Abkowitz et al., 2003; McKinneyFreeman and Goodell, 2004; Nygren et al., 2004). Given that there are 1,440 min per day and assuming an intravascular residence time of $5 \mathrm{~min}$ (Wright et al., 2001), we now estimate that 300-1,500 HSCs (and likely many more multipotent and oligopotent progenitors), representing up to $1-5 \%$ of the total pool, can briefly enter into the circulation each day in adult mice.

\section{Division-independent egress of HSCs}

If circulating HSCs egress from the bone marrow in a divisiondependent manner (Fig. $1 \mathrm{~A}$ ), after an appropriate period of BrdU feeding, this model of HSC egress would predict that all peripheral blood HSCs would have incorporated BrdU, whereas only a fraction of the bone marrow HSCs would have incorporated BrdU. More specifically, HSCs destined for peripheral blood would incorporate BrdU at more rapid rates than would the total pool of bone marrow HSCs. In contrast, the division-independent model (Fig. 1 B) would predict that after an appropriate labeling period, not all blood HSCs would have incorporated BrdU, and instead, the extent of BrdU incorporation would be similar to that of bone marrow HSCs. To test these models, 20 mice were fed BrdU in their drinking water for $3 \mathrm{~d}$, and the levels of BrdU incorporation in pooled peripheral blood and bone marrow HSCs were quantified. Only $\sim 9 \%$ of both blood and bone marrow HSCs had incorporated BrdU, suggesting that cellular division is not a requirement for HSC egress into the bloodstream (Fig. 4, experiment 1). Even after a longer BrdU feeding period of $6 \mathrm{~d}$ in which HSCs from 20 mice were pooled and analyzed, only $18 \%$ of peripheral blood and bone marrow HSCs had incorporated BrdU (Fig. 4, experiment 1). These experiments were repeated with similar results. After 9 and $12 \mathrm{~d}$ of BrdU feeding, the frequency of BrdU ${ }^{+}$HSCs found in the peripheral blood had still not exceeded that in the bone marrow (Fig. 4, experiments 2 and 3). Interestingly, the percentage of HSCs in the bone marrow that had incorporated BrdU did not change between 9 and $12 \mathrm{~d}$ of feeding, which is consistent with the proposal that distinct proliferative and relatively nonproliferative HSC populations exist (Nygren and Bryder, 2008; Wilson et al., 2008). It is possible that the actual levels of proliferation may be even less than these values indicate, as BrdU itself has been suggested to induce the proliferation of HSCs (Nygren and Bryder, 2008; Wilson et al., 2008). Our levels of BrdU incorporation in bone marrow HSCs are likely lower than that reported by two recent studies because of the lower dose of BrdU administered in this study (Kiel et al., 2007b; Wilson et al., 2008). This lower BrdU dose was still sufficient for distinguishing differences in proliferative rates, as highly proliferative myeloid progenitors had incorporated more BrdU than had
HSCs at all time points (Fig. 4). Thus, given the purity of these peripheral blood HSCs as shown by the clonal assays and in vivo reconstitutions (Fig. 3), it is clear from both experiments that not all peripheral blood HSCs incorporated BrdU, strengthening the interpretation that HSC intravasation need not necessarily be accompanied by cellular division.

Recent studies have shown that HSCs can circulate not only through the peripheral blood, but also through the lymph and other organs (Massberg et al., 2007). Thus, it remained possible that the HSCs in the blood that had not divided were cells that had in fact undergone egress from the bone marrow in a division-dependent manner before the labeling period, and had been circulating continuously for the duration of the BrdU feeding. To determine the maximum duration that HSCs can circulate and yet still retain their phenotypic identity, 10,000 single-sorted HSCs were transplanted into unconditioned wild-type animals and bone marrow HSC chimerism was measured between 1-7 d after transplant. Strikingly, no increase was observed in HSC chimerism between 1 and $3 \mathrm{~d}$ after transplantation, indicating that HSC homing to the marrow occurs rapidly after intravenous transplantation (Fig. 5, top), consistent with previous studies on partially purified HSCs (Nilsson et al., 1997, Plett et al., 2002). At both 1 and $3 \mathrm{~d}$ after transplant, most donor cells retained their phenotypic HSC identity (Fig. 5, bottom). A twofold increase in HSC chimerism did occur between 3 and $5 \mathrm{~d}$ after transplant (Fig. 5, top), but this was also accompanied by a reduction in the percentage of donor cells that retained their HSC surface phenotype, indicating differentiation (Fig. 5, bottom; Fig. S3). These data suggest that some transplanted HSCs must begin to divide and differentiate by $5 \mathrm{~d}$. Thus, the observed jump in HSC chimerism between 3 and $5 \mathrm{~d}$ may be partially caused by local proliferation rather than additional HSC homing from peripheral sites. Regardless, no further increases were observed between 5 and $7 \mathrm{~d}$ after transplant (Fig. 5, top), and the HSC chimerism values at these time points were similar to the values at $16 \mathrm{wk}$ after transplant when similar numbers of HSCs were infused in a single bolus (Fig. $6 \mathrm{~A}$, top). These data imply that few HSCs identified in the peripheral blood could have been circulating continuously for the duration of the BrdU labeling experiment in Fig. 4. The total number of HSCs found per spleen remained between 20 and 50 cells throughout the course of the experiment with no statistically significant differences observed, and we were unable to detect more than 1 donor HSC in the blood in any recipient at any time point (unpublished data). Collectively, these data confirm that HSCs can exit their supportive niches without dividing under physiological conditions.

\section{Niche vacancy under homeostatic conditions}

Division-independent HSC egress would be predicted to leave behind a small number of available niches for donor HSC transplantation, even in the absence of conditioning (Fig. 1 B). Moreover, because physiological HSC migration is thought to be a continuous process (Wright et al., 2001), 
division-independent egress would be predicted to lead to only a finite period of niche saturation after transplantation of an excess of donor HSCs. Previous studies have shown that repetitive injections of unfractionated bone marrow lead to more hematopoietic replacement than single-bolus injections of unfractionated marrow (Quesenberry et al., 1994; Colvin et al., 2004), although whether these findings apply to HSC replacement is currently unknown. Indeed, as HSCs comprise $<0.01 \%$ of all bone marrow cells, and because transplanted accessory cells can potentially clear endogenous HSCs and/or create additional niches (El-Badri et al., 1998; Slavin et al., 1998; Almeida-Porada et al., 1999), it is difficult to assess the intrinsic ability of donor HSCs to replace host HSCs in the absence of conditioning through unfractionated marrow transplants. To define the interval of HSC niche saturation, wild-type CD45.1 × CD45.2 animals were transplanted with a large single bolus of either 12,700 single-sorted (Fig. 6 A, top) or 11,070 double-sorted HSCs (Fig. $6 \mathrm{~A}$, bottom) or the same total number of HSCs administered over the course of 7 daily injections. The animals receiving the single bolus of

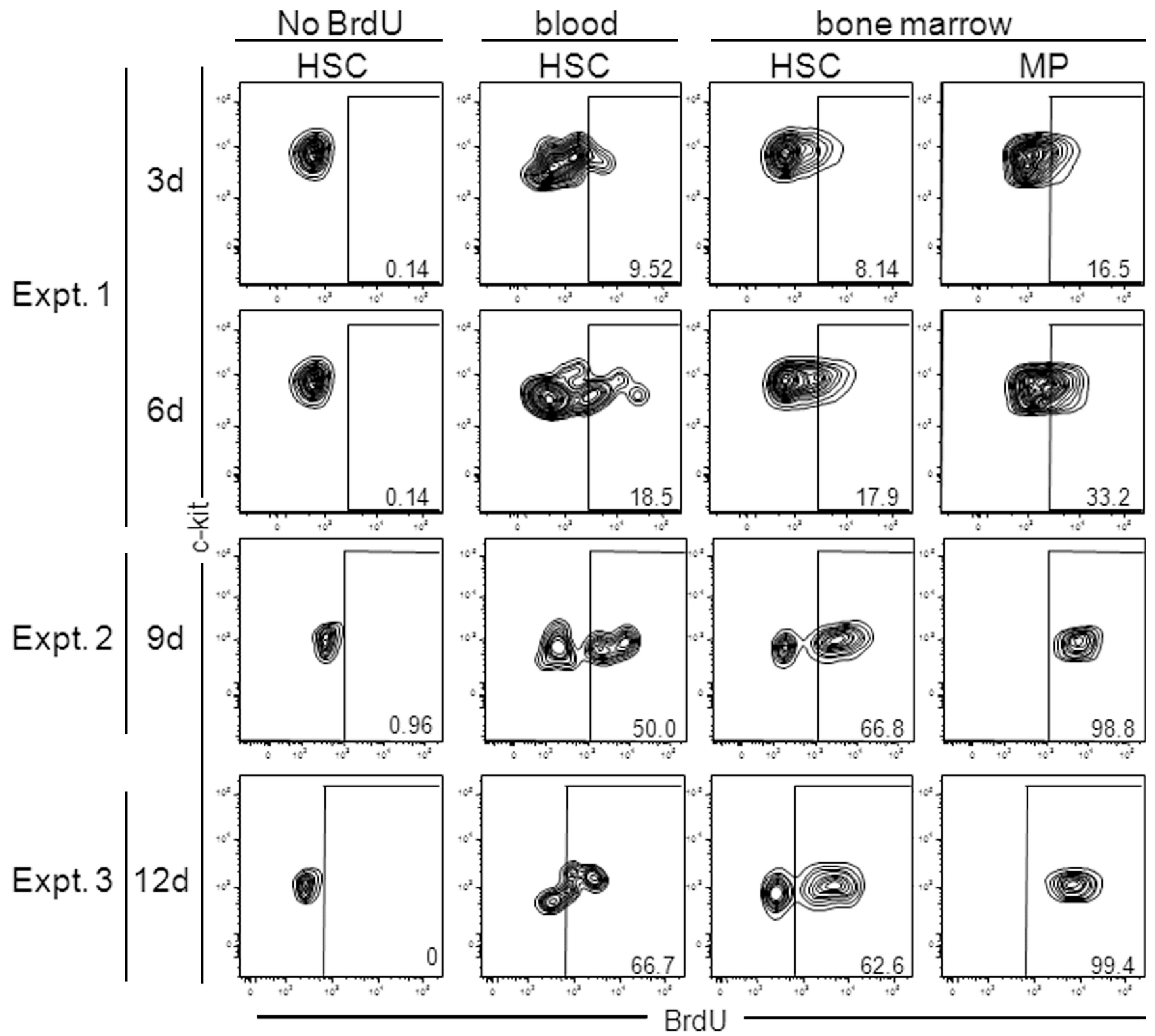

Figure 4. HSCs can egress into the peripheral blood without dividing. Mice were fed BrdU in the drinking water for 3 or $6 \mathrm{~d}$ (experiment 1), $9 \mathrm{~d}$ (experiment 2), or $12 \mathrm{~d}$ (experiment 3), and the percentage of peripheral blood HSCs that had incorporated BrdU was quantified. Control mice were not fed BrdU, but bone marrow HSCs were isolated as from experimental groups. HSCs were identified as described in Fig. 3 A, and myeloid progenitors (MP) were identified as lineage ${ }^{-}$c-kit ${ }^{+}$Sca- $1^{-}$cells. Peripheral blood was pooled from 20 mice for each experiment, and 2 independent experiments were performed for each time point. 
HSCs were injected six additional times daily (three times before HSC transplantation and three times afterward) with saline to control for mobilizing effects of the injections themselves. The group of mice that received daily HSC injections showed $2-2.5$-fold increases in bone marrow HSC chimerism, representing value ranges of $5-10 \%$, over the group that received a single bolus of HSCs, which displayed HSC chimerism values of $2-5 \%$, when sacrificed 16 wk after transplant (Fig. $6 \mathrm{~A}$ ). These data demonstrate that niche saturation after transplantation is transient.

Unlike in unconditioned immunodeficient recipients (Bhattacharya et al., 2006; Czechowicz et al., 2007), granulocyte chimerism correlated poorly with HSC chimerism in this wild-type setting, as has been previously observed in other studies (Wu and Keating, 1993). Peripheral blood
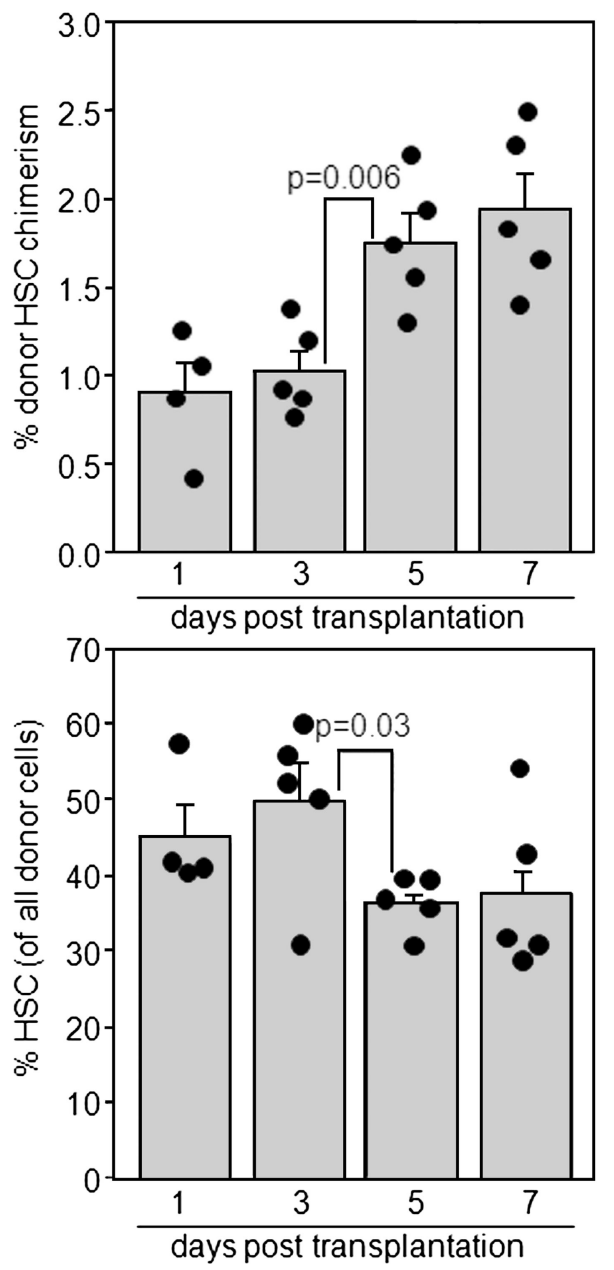

Figure 5. HSCs home to the bone marrow rapidly after transplantation. 10,000 purified CD45.1 HSCs were transplanted into unconditioned CD45.1 × CD45.2 wild-type recipients, and donor bone marrow HSC chimerism (top) and the percentage of donor cells that retained HSC phenotypes (bottom) were determined at the indicated time points ( $n=$ 4-5 mice for each time point). Mean chimerism values \pm SEM and $p$-values from the Students' unpaired two tailed $t$ test are shown. Two independent experiments were performed. granulocyte chimerism at the time of sacrifice underestimated the absolute HSC chimerism in individual mice, and did not show a linear relationship with HSC chimerism when examined in all recipients (Fig. $6 \mathrm{~B}$ ). Interestingly, when we transplanted CD $45.1 \times$ CD 45.2 mice with $6.5 \times 10^{7}$ unfractionated marrow cells from a CD45.1 donor, granulocyte chimerism after transplantation overestimated bone marrow HSC chimerism, but not overall KLS chimerism, demonstrating the unique and specific difficulty of replacing HSCs with transplanted cells (Fig. 6 C; Czechowicz et al., 2007). Thus, in this experimental system of unconditioned wild-type recipients, it appears that the most reliable method to measure bone marrow HSC chimerism is to quantify donor HSCs directly using stringent proper HSC markers. The biological basis for this difference between HSC chimerism and mature cell output is currently unclear, but has been observed before in other systems (Wu and Keating, 1993; Rossi et al., 2007). It is possible that the absences of certain cellular lineages and/or effects induced by different experimental manipulations can affect the extent to which HSC chimerism correlates with mature cell chimerism. Thus, different experimental conditions require independent verifications of these correlations. These differences may explain the discordance between our conclusions regarding transplanted $\mathrm{HSC}$ dose-dependent decreases in transplantation efficiencies (Fig. $7 \mathrm{~A}$ ) and other studies that inferred efficient HSC replacement based upon linear dosedependent replacement of total marrow (Bhattacharya et al., 2006; Czechowicz et al., 2007; Brecher et al., 1982; Stewart et al., 1993; Saxe et al., 1984; Wu and Keating, 1993; Colvin et al., 2004). Alternatively, it is possible that unfractionated marrow contains cells that can empty HSC niches through immunological clearance or through mobilization (Slavin et al., 1998). Finally, it is also possible that HSCs transplanted in the context of unfractionated marrow survive for longer durations than do purified HSCs (Benveniste et al., 2003), thus allowing these cells to engraft into empty niches as they become available over a longer period of time.

The existence of finite numbers of empty niches predicts that the likelihood of engraftment for any given cell within the transplant should decrease as the number of cells transplanted in a single bolus increases. Previous studies using unfractionated marrow transplants have given mixed answers to this prediction, with some studies suggesting an absolute linear dose-dependent replacement of host hematopoietic cells (Brecher et al., 1982), others demonstrating no dose-dependent increases in chimerism in certain mouse strains (Saxe et al., 1984), others finding no detectable engraftment in the absence of conditioning (Gambel et al., 1984), and still others finding dose-dependent curves intermediate to these findings (Rao et al., 1997). To experimentally determine this dosedependent efficiency of engraftment specifically for HSCs in the absence of immune barriers, we transplanted various numbers of purified CD45.2 HSCs into unconditioned wildtype CD45.1 $\times$ CD45.2 animals. At 4 wk after transplant, animals were sacrificed and bone marrow HSC chimerism was determined directly as in Fig. 6. The efficiency of 
engraftment of the lowest transplanted dose (250 HSCs) was approximately twofold higher than the efficiency of the 15,000 HSC dose (Fig. 7 A). Importantly, the efficiency of transplantation never approached zero, even at the highest transplanted HSC doses. These data are consistent with the concept that HSC niches are continuously being emptied and refilled, making complete saturation difficult to achieve.

Given that the efficiency of engraftment of low numbers of transplanted HSCs is approximately twofold higher than the efficiency of high doses of transplanted HSCs (Fig. 7 A), we estimated that multiple injections of low doses of HSCs would lead to twofold higher levels of HSC engraftment than single-bolus transplants (as in Fig. $6 \mathrm{~A}$ ) only if the number of empty HSC niches were being reset within the duration between the injections. In contrast, if niche availability were reset after longer periods of time, HSCs transplanted during later injections would encounter fewer available niches than those transplanted at the first injection, thereby reducing the overall efficiency of engraftment. Because the HSC engraftment from daily injections was more than twofold greater than that achieved by the single-bolus transplant (Fig. $6 \mathrm{~A}$ ), we estimate that HSC niche availability must be reset within at least $24 \mathrm{~h}$. Thus, we, for the first time, have specifically assessed the number of available HSC niches in normal wild-type animals and the rate of their emptying under steady-state conditions.
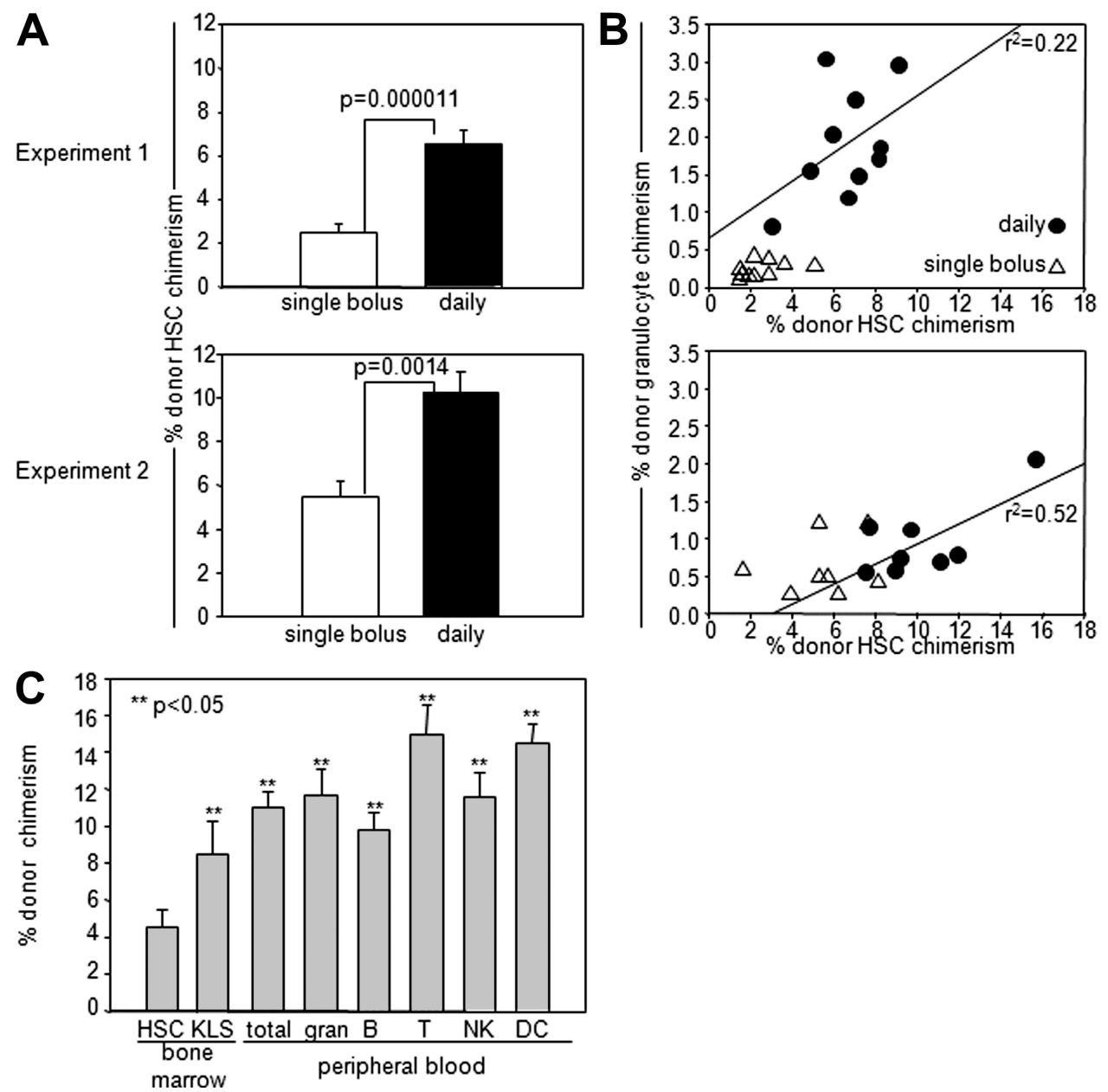

Figure 6. Niche availability is reset within $1 \mathrm{~d}$ in wild-type mice. (A) Daily transplantation yields higher levels of engraftment than single-bolus transplants. Wild-type CD45.1 × CD45.2 mice were transplanted with a sum total of 12,700 single-sorted bone marrow HSCs (experiment 1) or with 11,060 double-sorted bone marrow HSCs (experiment 2) given as a single bolus or over the course of 7 daily injections. At 16 wk after transplant, bone marrow was harvested and donor HSC (KLS CD150+ CD $\left.34^{-}\right)$chimerism was measured. Mean values \pm SEM are shown. $n=10$ for each group; repeat transplant experiments were performed three independent times, two of these are shown. (B) Peripheral blood granulocyte chimerism correlates poorly with donor HSC chimerism in unconditioned wild-type recipients. Granulocyte chimerism was correlated with HSC chimerism in each individual mouse 16 wk after transplantation. $R^{2}$ value from linear regression is shown. Repeat transplant experiments were performed 3 independent times, 2 of these are shown. (C) Mature cell chimerism correlates poorly with HSC chimerism after whole bone marrow transplantation. $6.5 \times 10^{7}$ unfractionated nucleated bone marrow cells from wild-type female CD45.2 mice were transplanted into unirradiated wild-type female CD45.1 $\times$ CD45.2 F1 recipients $(n=5)$; 2 independent experiments were performed. Total peripheral blood, BM HSC (defined as KLS CD 135-CD34-), BM total KLS, and granulocyte, B cell, T cell, natural killer cell (NK), and dendritic cell (DC) chimerism in the peripheral blood was measured $16 \mathrm{wk}$ after transplantation. 
To verify that our surface phenotypic characterization accurately identified functional donor HSCs, we transplanted 12-14 single-sorted phenotypic donor HSCs from unirradiated primary transplanted recipients into lethally irradiated secondary recipients. At $16 \mathrm{wk}$ after secondary transplant, multilineage engraftment derived from these reisolated donor HSCs was observed in 5/7 recipients (Fig. 7 B). These data confirm that we are accurately quantifying donor HSC chimerism in the primary unirradiated transplanted recipients.

\section{Apoptosis does not play a role in HSC niche clearance}

Aside from the division-independent egress of HSCs, apoptosis of HSCs might also lead to the emptying of appropriate niches. To test this hypothesis, $\sim 2,500$ single-sorted $\mathrm{Bcl} 2$ transgenic CD45.2 HSCs were transplanted into unconditioned CD45.1 × CD45.2 Bcl2-transgenic mice, which show increased numbers of HSCs through the prevention of apoptosis (Domen and Weissman, 2000), or into wild-type CD45.1 $\times$ CD45.2 animals. Bone marrow HSC chimerism levels were similar between the 2 groups of recipients at $16 \mathrm{wk}$ after transplantation (Fig. 8). These data suggest that host HSC apoptosis is not a major mechanism of niche clearance within the timeframe that transplanted HSCs engraft.

\section{DISCUSSION}

The ability of transplanted HSCs to home to the bone marrow and reconstitute the recipient's blood supply is the basis for the routine use of bone marrow transplants to correct both inherited and acquired hematopoietic disorders. The success of these treatments is contingent upon the replacement of the malfunctioning endogenous HSCs with normal donor HSCs. The need for ablating host HSCs before transplantation to achieve high levels of donor HSC engraftment has been a hotly debated issue over the years, with several groups claiming efficient HSC replacement in the absence of prior cytoreductive conditioning of the host (Brecher et al., 1982; Saxe et al., 1984; Stewart et al., 1993; Wu and Keating, 1993; Rao et al., 1997; Colvin et al., 2004), whereas experimental and clinical studies from our group and others found little evidence for extensive HSC replacement in unconditioned recipients (Gambel et al., 1984; Müller et al., 2000; van Os et al., 2001; Prockop and Petrie, 2004; Xu et al., 2004; Bhattacharya et al., 2006; Cavazzana-Calvo et al., 2007; Czechowicz et al., 2007). Our studies specifically examined the behavior of purified HSCs and HSC replacement rather than that of unfractionated marrow; thus, we believe our results are more reliable than previous and often conflicting estimates based on whole-marrow transplants (Brecher et al., 1982; Saxe et al., 1984; Gambel et al., 1984; Stewart et al., 1993; Wu and Keating, 1993; Quesenberry et al., 1994; Rao et al., 1997; Stewart et al., 1998; Colvin et al., 2004). This is particularly important because clinical unfractionated bone marrow transplants are associated with high rates of acute graft versus host disease, and as such most transplants are performed with HSC-enriched populations.

Although the exact amount of HSC replacement that occurs in the absence of conditioning is still controversial, it is clear that a certain fraction of transplanted HSCs do engraft in unconditioned recipients, a finding that appears to be inconsistent with the assumptions that the number of HSC niches is equivalent to the number of HSCs (Moore et al., 1997) and that HSCs remain fixed into place within these physically discrete niches (Schofield, 1978). In this study, we provide evidence for a model that is consistent with both the existence of physically discrete HSC niches and HSC replacement by transplanted cells in the absence of conditioning.
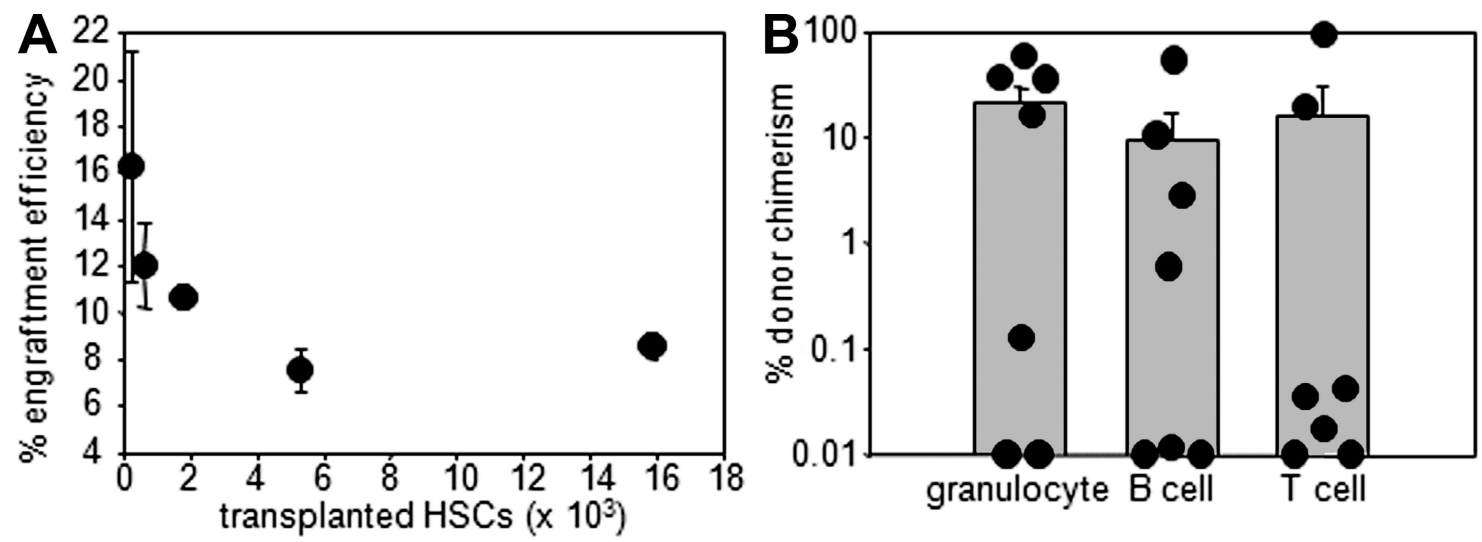

Figure 7. Functional HSC engraftment efficiency decreases with transplanted cell dose. A. Engraftment efficiency decreases with transplanted cell dose. Various numbers of purified CD45.1 HSCs were transplanted into unconditioned CD $45.1 \times$ CD 45.2 mice, and bone marrow HSC chimerism was determined 4 wk after transplant. Efficiency was calculated using the measured chimerism and with the approximation that 12-16-wk-old mice have 25,000 endogenous HSCs as follows: Efficiency $=(\%$ chimerism $\times$ cell dose $) /(25,000)$ Mean values \pm SEM are shown. $n=5$ for each condition; two independent experiments were performed. B. Donor HSCs can be secondarily transplanted. 12-14 single-sorted donor CD45.2 HSCs from unconditioned transplanted wild-type CD $45.1 \times$ CD 45.2 mice were reisolated at 16 wk after primary transplant and secondarily transplanted into lethally irradiated CD45.1 mice along with 200,000 GFP+ unfractionated bone marrow cells. The total percent chimerism for each lineage derived from CD45.2 HSCs is shown at 16 wk after transplant. Mean chimerism \pm SEM is shown $(n=7)$. Two independent experiments were performed. 


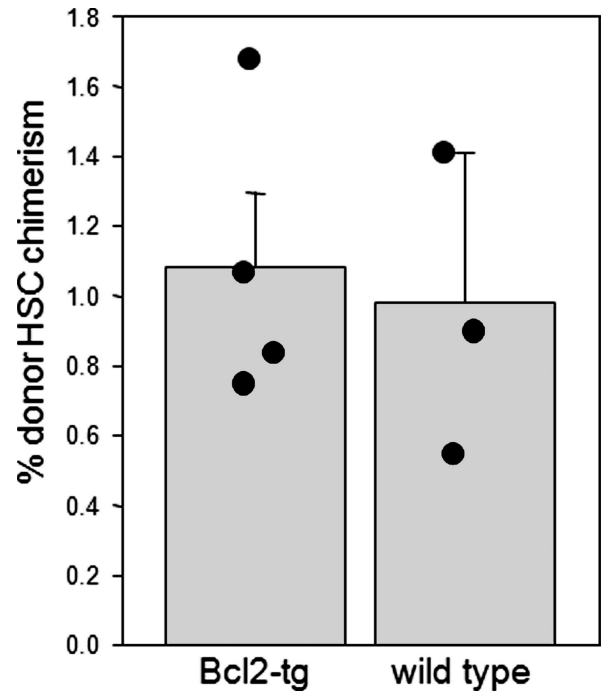

Figure 8. Apoptosis is not a major mechanism of HSC niche clearance. 2,500 single-sorted bone marrow HSCs ( $\sim 45 \%$ purity) from $\mathrm{H}-2^{k}$ $\mathrm{BCl}-2$ transgenic $\mathrm{CD} 45.2$ mice were transplanted into unconditioned $\mathrm{H}-2^{\mathrm{k}}$-BCl-2 transgenic CD45.1 $\times$ CD45.2 mice $(n=4)$ or wild-type CD $45.1 \times$ CD45.2 mice $(n=3)$. Mean donor bone marrow HSC chimerism \pm SEM was quantified 16 wk after transplantation. Two independent experiments were performed.

In this model, the division-independent egress of HSCs leaves behind a certain fraction of empty niches that can be filled by transplanted HSCs, thus leading to the functional replacement of a small fraction of endogenous HSCs.

Genetic deficiencies in genes such as Egr1 and certain mobilizing regimens such as cyclophosphamide + G-CSF appear to trigger a large amount of proliferation of bone marrow HSCs, along with the egress of HSCs into the blood, spleen, and liver (Morrison et al., 1997; Min et al., 2008), perhaps by causing an excess of HSCs relative to the number of available niches available in the marrow. These mobilizing regimens have been shown to not be effective as transplantation conditioning regimens (Robinson et al., 2000). On the other hand, the CXCR 4 antagonist AMD3100, interleukin-8, and blocking antibodies or antagonistic small molecules against VLA-4 all cause HSC release into the bloodstream in the apparent absence of cellular division, suggesting settings in which there is no absolute requirement for proliferation before HSC egress (Laterveer et al., 1995; Craddock et al., 1997; Broxmeyer et al., 2005; Chen et al., 2006; Ramirez et al., 2009). These types of mobilizing agents have been shown to be effective as transplantation conditioners (Chen et al., 2006). Consistent with these latter findings, our results using $\mathrm{BrdU}$ incorporation indicate that under steady-state conditions, HSCs need not proliferate to egress into circulation from their supportive niches. This process allows a certain degree of HSC replacement to occur after transplantation, even in the absence of cytoreduction.

Given that the physiological circulation of HSCs is continuous, the division-independent egress of HSCs would be expected to generate a process by which HSC niches are continuously being emptied, refilled, and recycled. Consistent with such a mechanism, we demonstrate that transplantation of an excess of donor HSCs reveals these transiently vacant niches and leads to the replacement of a certain fraction of host HSCs. Collectively, our data suggest that engraftment of transplanted HSCs is limited by the number of empty niches that arise while the transplanted cells survive. We thus propose a two-phase model of donor HSC engraftment: in the first phase, the niches that are already available at the time of transplant are efficiently engrafted by a portion of the transplanted HSCs through nonstochastic chemotaxis and adhesion. In the second phase, the remaining transplanted HSCs survey for unoccupied niches until they differentiate or die; the likelihood of encountering a niche that becomes vacated by host HSC egress is dependent on the number of cells transplanted and the subsequent concentration of donor HSCs in the recipient animal.

Although HSCs are known to migrate between HSCsupportive niches at different sites during embryonic development (Moore and Metcalf, 1970; Johnson and Moore, 1975; Gekas et al., 2005; Samokhvalov et al., 2007), we do not know or test here what fraction of endogenously migrating HSC in the adult are destined to reenter HSC niches; some could be fated for non self-renewing multipotent progenitor (MPP) niches, or even specialized niches, perhaps for the production of selected lineages such as megakaryocytes and erythrocytes. Indeed, the ability of circulating HSCs to reenter appropriate bone marrow HSC niches under homeostatic conditions has been suggested to be low by several studies (Abkowitz et al., 2003; McKinney-Freeman and Goodell, 2004). Therefore it is still a question whether MPP niches are physically proximal to HSC niches or positioned at entry sites from the vasculature that ends in sinusoids.

Although apoptosis of endogenous HSCs does not appear to be a major mechanism by which niches are emptied, it is important to note that our data do not exclude other potential mechanisms by which niches might be emptied under physiological conditions. For example, the number of HSCs expands dramatically with age, with 5-10 fold increases in HSC numbers in 24-mo-old animals vs. 12-wk-old animals (Harrison et al., 1989; Morrison et al., 1996; de Haan and Van Zant, 1999; Sudo et al., 2000; Rossi et al., 2005). It is possible that the number of HSC niches also expands and precedes the HSC expansion slightly, leading to transient periods of niche vacancy. This process would be predicted to generate an $\sim 0.2 \%$ increase in the number of niches every day. These numbers are insufficient to explain the levels of engraftment achieved in unconditioned animals, but such processes may contribute to HSC replacement after transplantation. Formal testing of this hypothesis will require the precise identification of the cellular components of the niche. Additional processes such as bone remodeling may also play a role in the creation of new niches and/or HSC egress under steady-state conditions (Kollet et al., 2006).

Our data suggest that in clinical HSC transplantation settings where cytoreductive conditioning is not applied, such 
as for the treatment of severe combined immunodeficiency (Gatti et al., 1968; Buckley et al., 1999), the levels of HSC engraftment, which are generally very poor (Müller et al., 2000; Cavazzana-Calvo et al., 2007), might be improved by capitalizing on the physiological egress of HSCs through the repetitive transplantation of smaller doses of donor HSCs. Moreover, our study provides a model that is consistent with host HSC replacement after donor HSC transplantation in unconditioned recipients, yet is also consistent with data suggesting the existence of a physically discrete niche that effectively retains and regulates HSCs.

\section{MATERIALS AND METHODS}

Mice. All animal procedures were approved by the International Animal Care and Use Committee and Stanford University's Administrative Panel on Laboratory Animal Care. Recipient mice used in these studies were 8-12wk-old wild-type C57BL/Ka CD45.1, CD45.2, or CD45.1 × CD45.2 wild-type or H-2k Bcl2-transgenic mice (Domen and Weissman, 2000). Donor mice used were 10-12-wk congenically distinguishable CD45.1 or CD45.2 C57BL/Ka wild-type or H-2k Bcl2-transgenic mice (Domen and Weissman, 2000). All mouse strains were bred and maintained at Stanford University's Research Animal Facility.

HSC transplantation. Bone marrow was harvested from donor mice by crushing bones and removing debris on a density gradient using Histopaque 1119 (Sigma-Aldrich). Bone marrow was then ${\mathrm{c}-\mathrm{kit}^{+} \text {enriched using CD117 }}^{+}$ microbeads (AutoMACS; Miltenyi Biotec). Peripheral blood was isolated from the tail vein where indicated, or by puncture of the right atrium and perfusion of PBS + $10 \mathrm{mM}$ EDTA through the left ventricle of tribromoethanol-anesthetized mice. Erythrocytes were removed using a 1:1 gradient mixture of Histopaque 1119 and 1077. Cells were stained with antibodies described below and HSCs were isolated by single or double FACS based on previously defined reactivity for particular cell surface markers (Lineage ${ }^{-}$ c-kit ${ }^{+} \mathrm{Sca}-1^{+} \mathrm{IL}-7 \mathrm{ra} \alpha^{-} \mathrm{CD} 27^{+} \mathrm{CD} 150^{+} \mathrm{CD} 34^{-}$) on a FACSAria (BD). Cells were transplanted by retroorbital injection. In some cases, $200 \mu \mathrm{l}$ peripheral blood was collected from the tail vein of unmanipulated wild-type mice in heparinized tubes, washed once with PBS $+10 \mathrm{mM}$ EDTA, and injected into lethally irradiated recipients alongside $2 \times 10^{5}$ competitor bone marrow from congenically distinguishable $\mathrm{GFP}^{-}$transgenic wild-type mice.

Antibodies. The following monoclonal antibodies were purified and conjugated using hybridomas maintained in our laboratory: 2C11 (anti-CD3), GK1.5 (anti-CD4), 53-6.7 (anti-CD8), 6B2 (anti-B220), 8C5 (anti-Gr-1), M1/70 (anti-Mac-1), TER119 (anti-Ter119), A20.1.7 (anti-CD45.1), AL14A2 (anti-CD45.2), 2B8 (anti-c-kit), and E13-161-7 (anti-Sca-1). Antibodies were conjugated to biotin, Pacific blue, PE, allophycocyanin (APC), Alexa Fluor 488, Alexa Fluor 647, or Alexa Fluor 680 (Invitrogen), according to the manufacturer's instructions. The following were purchased from eBioscience: antibodies against CD3, CD4, CD8, B220, Mac-1, Ter119, and Gr-1 conjugated to PE-Cy5; anti-c-kit and anti-Mac-1 conjugated to PE-Cy7; antiCD135 (A2F10) conjugated to PE, PE-Cy5, and biotin; anti-CD34 conjugated to FITC, Alexa Fluor 647, Alexa Fluor 700, and biotin; anti-CD27 conjugated to APC (LG.7F9); and anti-B220 conjugated to APC-Cy7. Anti-CD150 conjugated to PE and to Alexa Fluor 647 was purchased from BioLegend. Streptavidin conjugated to Alexa Fluor 488 and Alexa Fluor 680, and goat anti-rat conjugated to Alexa Fluor 488 was purchased from Invitrogen. Streptavidin conjugated to Quantum Dot 605 was purchased from Invitrogen. Anti-BrdU conjugated to FITC was purchased from BD.

Clonal in vitro assays. Single cells were deposited using the ACDU unit of the BD FACSAria into individual wells of a 96-well round bottom plate containing $150 \mu \mathrm{LMEM} / \mathrm{F} 12$ (Invitrogen) with $10 \mathrm{ng} / \mathrm{ml}$ each of stem cell factor (SCF; Peprotech), thrombopoietin (TPO; Peprotech), Flt3 ligand
(eBioscience), IL-3 (Peprotech), GM-CSF (Peprotech), erythropoietin (EPO; R\&D Systems), and 10\% fetal bovine serum (HyClone). Wells were harvested after $12 \mathrm{~d}$, cytospins were prepared and stained with May-Giemsa, and colonies were visually scored for lineage output.

BrdU analysis. C57BL $/ 6$ mice were maintained on $0.8 \mathrm{mg} / \mathrm{ml} \mathrm{BrdU}$ in their drinking water for 3-12 d. The bottles containing BrdU water were protected from light and changed daily. To obtain peripheral blood, the mice were perfused with PBS containing $10 \mathrm{mM}$ EDTA and erythrocytes were removed using Histopaque gradients as before. The bone marrow was harvested from the mice by crushing bones and removing debris on density gradient using Histopaque 1119 (Sigma-Aldrich). Cells from peripheral blood and bone marrow were stained with antibodies as described in the Antibodies section of Materials and methods. The cells were fixed and permeabilized using the Fix and Perm kit (Invitrogen). The cells were subjected to DNaseI treatment for $45 \mathrm{~min}$ at room temperature, and BrdU incorporation was visualized using Anti-BrdU antibody conjugated to FITC.

Engraftment analysis. Blood was obtained from the tail vein of transplanted mice at various time points, and erythrocytes were sedimented using $2 \%$ dextran in $\mathrm{PBS}$ at $37^{\circ} \mathrm{C}$ for $30 \mathrm{~min}$, and supernatants were subsequently lysed using ACK lysis buffer $\left(150 \mathrm{mM} \mathrm{NH}_{4} \mathrm{Cl}, 1 \mathrm{mM} \mathrm{KHCO}_{3}\right.$, and $0.1 \mathrm{mM}$ EDTA) for $5 \mathrm{~min}$. Cells were stained with antibodies described in the Antibodies section of Materials and methods and analyzed on the BD FACSAria. Donor granulocyte chimerism was determined by analyzing the percentage of Ter119-CD3-B220-Gr-1 ${ }^{\text {high }}$ side scatter ${ }^{\text {high }}$ cells that were also donor ${ }^{+}$.

Online supplemental material. Fig. S1 shows HSC activities in $\mathrm{CD} 27^{+}$ and $\mathrm{CD} 27^{-}$fractions of bone marrow and blood. Fig. S2 shows frequency of reconstitution and multilineage chimerism after unfractionated blood transplantation into irradiated recipients. Fig. S3 shows representative surface phenotypes of donor cells at various times after transplantation of HSCs into unirradiated recipients. Online supplemental material is available at http:// www.jem.org/cgi/content/full/jem.20090778/DC1.

We thank L. Jerabek for laboratory management, C. Muscat for antibody production, A. Mosley, J. Dollaga, and D. Escoto for animal care.

This investigation was supported by National Institutes of Health grants R01CA086065 and R01HL058770 (to I.L. Weissman). D. Bhattacharya was supported by a fellowship from the Cancer Research Institute and National Institutes of Health grants T32Al0729022 and K01DK078318. A. Czechowicz is a Howard Hughes Medical Institute Medical Research Training Fellow, and was supported by a fellowship from the Medical Scholars Program at Stanford University School of Medicine. Research for this article was supported in part by a grant from The Paul and Daisy Soros Fellowships for New Americans. The program is not responsible for the views expressed. A.G.L. Ooi was supported by a scholarship from the Singapore National Agency for Science, Technology, and Research; D.J. Rossi was supported by National Institutes of Health grant ROOAG029760; and D. Bryder was supported by a scholarship from the Swedish Medical Research Council (STINT).

Affiliations that might be perceived to have biased this work are as follows: I.L. Weissman cofounded Systemix, Stem Cells, Inc., and Cellerant, Inc. All other authors have no conflicting financial interests.

\section{Submitted: 8 April 2009}

Accepted: 5 October 2009

\section{REFERENCES}

Abkowitz, J.L., A.E. Robinson, S. Kale, M.W. Long, and J. Chen. 2003 Mobilization of hematopoietic stem cells during homeostasis and after cytokine exposure. Blood. 102:1249-1253. doi:10.1182/blood-2003-01-0318

Allman, D., A. Sambandam, S. Kim, J.P. Miller, A. Pagan, D. Well, A. Meraz, and A. Bhandoola. 2003. Thymopoiesis independent of common lymphoid progenitors. Nat. Immunol. 4:168-174. doi:10.1038/ni878

Almeida-Porada, G., A.W. Flake, H.A. Glimp, and E.D. Zanjani. 1999 Cotransplantation of stroma results in enhancement of engraftment and early expression of donor hematopoietic stem cells in utero. Exp. Hematol. 27:1569-1575. doi:10.1016/S0301-472X(99)00090-9 
Arai, F., A. Hirao, M. Ohmura, H. Sato, S. Matsuoka, K. Takubo, K. Ito, G.Y. Koh, and T. Suda. 2004. Tie2/angiopoietin-1 signaling regulates hematopoietic stem cell quiescence in the bone marrow niche. Cell. 118:149-161. doi:10.1016/j.cell.2004.07.004

Benveniste, P., C. Cantin, D. Hyam, and N.N. Iscove. 2003. Hematopoietic stem cells engraft in mice with absolute efficiency. Nat. Immunol. 4:708713. doi:10.1038/ni940

Bhattacharya, D., D.J. Rossi, D. Bryder, and I.L. Weissman. 2006. Purified hematopoietic stem cell engraftment of rare niches corrects severe lymphoid deficiencies without host conditioning. J. Exp. Med. 203:73-85. doi:10.1084/jem.20051714

Brecher, G., J.D. Ansell, H.S. Micklem, J.H. Tjio, and E.P. Cronkite. 1982. Special proliferative sites are not needed for seeding and proliferation of transfused bone marrow cells in normal syngeneic mice. Proc. Natl. Acad. Sci. USA. 79:5085-5087. doi:10.1073/pnas.79.16.5085

Broxmeyer, H.E., C.M. Orschell, D.W. Clapp, G. Hangoc, S. Cooper, P.A. Plett, W.C. Liles, X. Li, B. Graham-Evans, T.B. Campbell, et al. 2005. Rapid mobilization of murine and human hematopoietic stem and progenitor cells with AMD3100, a CXCR4 antagonist. J. Exp. Med. 201:1307-1318. doi:10.1084/jem.20041385

Bryder, D., D.J. Rossi, and I.L. Weissman. 2006. Hematopoietic stem cells: the paradigmatic tissue-specific stem cell. Am. J. Pathol. 169:338-346. doi:10.2353/ajpath.2006.060312

Buckley, R.H., S.E. Schiff, R.I. Schiff, L. Markert, L.W. Williams, J.L. Roberts, L.A. Myers, and F.E. Ward. 1999. Hematopoietic stem-cell transplantation for the treatment of severe combined immunodeficiency. N. Engl. J. Med. 340:508-516. doi:10.1056/NEJM199902183400703

Calvi, L.M., G.B. Adams, K.W. Weibrecht, J.M. Weber, D.P. Olson, M.C. Knight, R.P. Martin, E. Schipani, P. Divieti, F.R. Bringhurst, et al. 2003. Osteoblastic cells regulate the haematopoietic stem cell niche. Nature. 425:841-846. doi:10.1038/nature02040

Camargo, F.D., S.M. Chambers, E. Drew, K.M. McNagny, and M.A. Goodell. 2006. Hematopoietic stem cells do not engraft with absolute efficiencies. Blood. 107:501-507. doi:10.1182/blood-2005-02-0655

Cavazzana-Calvo, M., F. Carlier, F. Le Deist, E. Morillon, P. Taupin, D. Gautier, I. Radford-Weiss, S. Caillat-Zucman, B. Neven, S. Blanche, et al. 2007. Long-term T-cell reconstitution after hematopoietic stem-cell transplantation in primary T-cell-immunodeficient patients is associated with myeloid chimerism and possibly the primary disease phenotype. Blood. 109:4575-4581. doi:10.1182/blood-2006-07-029090

Chen, J., A. Larochelle, S. Fricker, G. Bridger, C.E. Dunbar, and J.L. Abkowitz. 2006. Mobilization as a preparative regimen for hematopoietic stem cell transplantation. Blood. 107:3764-3771. doi:10.1182/ blood-2005-09-3593

Colvin, G.A., J.F. Lambert, M. Abedi, C.C. Hsieh, J.E. Carlson, F.M. Stewart, and P.J. Quesenberry. 2004. Murine marrow cellularity and the concept of stem cell competition: geographic and quantitative determinants in stem cell biology. Leukemia. 18:575-583. doi:10.1038/sj.leu .2403268

Craddock, C.F., B. Nakamoto, R.G. Andrews, G.V. Priestley, and T. Papayannopoulou. 1997. Antibodies to VLA4 integrin mobilize longterm repopulating cells and augment cytokine-induced mobilization in primates and mice. Blood. 90:4779-4788.

Czechowicz, A., D. Kraft, I.L. Weissman, and D. Bhattacharya. 2007. Efficient transplantation via antibody-based clearance of hematopoietic stem cell niches. Science. 318:1296-1299. doi:10.1126/science.1149726

de Haan, G., and G. Van Zant. 1999. Dynamic changes in mouse hematopoietic stem cell numbers during aging. Blood. 93:3294-3301.

Domen, J., and I.L. Weissman. 2000. Hematopoietic stem cells need two signals to prevent apoptosis; BCL-2 can provide one of these, Kitl/ c-Kit signaling the other. J. Exp. Med. 192:1707-1718. doi:10.1084/jem .192 .12 .1707

El-Badri, N.S., B.Y. Wang, Cherry, and R.A. Good. 1998. Osteoblasts promote engraftment of allogeneic hematopoietic stem cells. Exp. Hematol. 26:110-116

Ema, H., K. Sudo, J. Seita, A. Matsubara, Y. Morita, M. Osawa, K. Takatsu, S. Takaki, and H. Nakauchi. 2005. Quantification of self-renewal capacity in single hematopoietic stem cells from normal and Lnk-deficient mice. Dev. Cell. 8:907-914. doi:10.1016/j.devcel.2005.03.019
Ernst, B., D.S. Lee, J.M. Chang, J. Sprent, and C.D. Surh. 1999. The peptide ligands mediating positive selection in the thymus control $\mathrm{T}$ cell survival and homeostatic proliferation in the periphery. Immunity. 11:173-181. doi:10.1016/S1074-7613(00)80092-8

Förster, I., and K. Rajewsky. 1990. The bulk of the peripheral B-cell pool in mice is stable and not rapidly renewed from the bone marrow. Proc. Natl. Acad. Sci. USA. 87:4781-4784. doi:10.1073/pnas.87.12.4781

Gambel, P., L.H. Francescutti, and T.G. Wegmann. 1984. Antibodyfacilitated chimeras. Stem cell allotransplantation using antihost major histocompatibility complex monoclonal antibodies instead of lethal irradiation for host conditioning. Transplantation. 38:152-158. doi:10.1097/ 00007890-198408000-00012

Gatti, R.A., H.J. Meuwissen, H.D. Allen, R. Hong, and R.A. Good. 1968. Immunological reconstitution of sex-linked lymphopenic immunological deficiency. Lancet. 2:1366-1369. doi:10.1016/S0140-6736(68)92673-1

Gekas, C., F. Dieterlen-Lièvre, S.H. Orkin, and H.K. Mikkola. 2005. The placenta is a niche for hematopoietic stem cells. Dev. Cell. 8:365-375. doi:10.1016/j.devcel.2004.12.016

Goldrath, A.W., and M.J. Bevan. 1999. Low-affinity ligands for the TCR drive proliferation of mature CD8+ T cells in lymphopenic hosts. Immunity. 11:183-190. doi:10.1016/S1074-7613(00)80093-X

Goodman, J.W., and G.S. Hodgson. 1962. Evidence for stem cells in the peripheral blood of mice. Blood. 19:702-714.

Harrison, D.E., C.M. Astle, and M. Stone. 1989. Numbers and functions of transplantable primitive immunohematopoietic stem cells. Effects of age. J. Immunol. 142:3833-3840.

Haug, J.S., X.C. He, J.C. Grindley, J.P. Wunderlich, K. Gaudenz, J.T. Ross, A. Paulson, K.P. Wagner, Y. Xie, R. Zhu, et al. 2008. N-cadherin expression level distinguishes reserved versus primed states of hematopoietic stem cells. Cell Stem Cell. 2:367-379. doi:10.1016/j.stem .2008 .01 .017

Johnson, G.R., and M.A. Moore. 1975. Role of stem cell migration in initiation of mouse foetal liver haemopoiesis. Nature. 258:726-728. doi: $10.1038 / 258726 \mathrm{a} 0$

Kiel, M.J., O.H. Yilmaz, T. Iwashita, O.H. Yilmaz, C. Terhorst, and S.J. Morrison. 2005. SLAM family receptors distinguish hematopoietic stem and progenitor cells and reveal endothelial niches for stem cells. Cell. 121:1109-1121. doi:10.1016/j.cell.2005.05.026

Kiel, M.J., G.L. Radice, and S.J. Morrison. 2007a. Lack of evidence that hematopoietic stem cells depend on $\mathrm{N}$-cadherin-mediated adhesion to osteoblasts for their maintenance. Cell Stem Cell. 1:204-217. doi:10.1016/ j.stem.2007.06.001

Kiel, M.J., S. He, R. Ashkenazi, S.N. Gentry, M. Teta, J.A. Kushner, T.L. Jackson, and S.J. Morrison. 2007b. Haematopoietic stem cells do not asymmetrically segregate chromosomes or retain BrdU. Nature. 449:238-242. doi:10.1038/nature06115

Kollet, O., A. Dar, S. Shivtiel, A. Kalinkovich, K. Lapid, Y. Sztainberg, M. Tesio, R.M. Samstein, P. Goichberg, A. Spiegel, et al. 2006. Osteoclasts degrade endosteal components and promote mobilization of hematopoietic progenitor cells. Nat. Med. 12:657-664. doi:10.1038/nm1417

Laterveer, L., I.J. Lindley, M.S. Hamilton, R. Willemze, and W.E. Fibbe. 1995. Interleukin-8 induces rapid mobilization of hematopoietic stem cells with radioprotective capacity and long-term myelolymphoid repopulating ability. Blood. 85:2269-2275.

Lazarus, H.M., O.N. Koc, S.M. Devine, P. Curtin, R.T. Maziarz, H.K. Holland, E.J. Shpall, P. McCarthy, K. Atkinson, B.W. Cooper, et al. 2005. Cotransplantation of HLA-identical sibling culture-expanded mesenchymal stem cells and hematopoietic stem cells in hematologic malignancy patients. Biol. Blood Marrow Transplant. 11:389-398. doi:10.1016/j.bbmt.2005.02.001

Massberg, S., P. Schaerli, I. Knezevic-Maramica, M. Köllnberger, N. Tubo, E.A. Moseman, I.V. Huff, T. Junt, A.J. Wagers, I.B. Mazo, and U.H. von Andrian. 2007. Immunosurveillance by hematopoietic progenitor cells trafficking through blood, lymph, and peripheral tissues. Cell. 131:994-1008. doi:10.1016/j.cell.2007.09.047

Matsuzaki, Y., K. Kinjo, R.C. Mulligan, and H. Okano. 2004. Unexpectedly efficient homing capacity of purified murine hematopoietic stem cells. Immunity. 20:87-93. doi:10.1016/S1074-7613(03)00354-6 
McCredie, K.B., E.M. Hersh, and E.J. Freireich. 1971. Cells capable of colony formation in the peripheral blood of man. Science. 171:293-294. doi:10.1126/science.171.3968.293

McKinney-Freeman, S., and M.A. Goodell. 2004. Circulating hematopoietic stem cells do not efficiently home to bone marrow during homeostasis. Exp. Hematol. 32:868-876. doi:10.1016/j.exphem. 2004.06.010

Méndez-Ferrer, S., D. Lucas, M. Battista, and P.S. Frenette. 2008. Haematopoietic stem cell release is regulated by circadian oscillations. Nature. 452:442-447. doi:10.1038/nature06685

Min, I.M., G. Pietramaggiori, F.S. Kim, E. Passegué, K.E. Stevenson, and A.J. Wagers. 2008. The transcription factor EGR1 controls both the proliferation and localization of hematopoietic stem cells. Cell Stem Cell. 2:380-391. doi:10.1016/j.stem.2008.01.015

Moore, M.A., and D. Metcalf. 1970. Ontogeny of the haemopoietic system: yolk sac origin of in vivo and in vitro colony forming cells in the developing mouse embryo. Br. J. Haematol. 18:279-296. doi:10.1111/ j.1365-2141.1970.tb01443.x

Moore, K.A., H. Ema, and I.R. Lemischka. 1997. In vitro maintenance of highly purified, transplantable hematopoietic stem cells. Blood. 89:4337-4347.

Morrison, S.J., A.M. Wandycz, K. Akashi, A. Globerson, and I.L. Weissman. 1996. The aging of hematopoietic stem cells. Nat. Med. 2:1011-1016. doi:10.1038/nm0996-1011

Morrison, S.J., D.E. Wright, and I.L. Weissman. 1997. Cyclophosphamide/ granulocyte colony-stimulating factor induces hematopoietic stem cells to proliferate prior to mobilization. Proc. Natl. Acad. Sci. USA. 94:19081913. doi:10.1073/pnas.94.5.1908

Müller, S.M., T. Kohn, A.S. Schulz, K.M. Debatin, and W. Friedrich. 2000. Similar pattern of thymic-dependent T-cell reconstitution in infants with severe combined immunodeficiency after human leukocyte antigen (HLA)-identical and HLA-nonidentical stem cell transplantation. Blood. 96:4344-4349.

Nilsson, S.K., M.S. Dooner, C.Y. Tiarks, H.U. Weier, and P.J. Quesenberry, 1997. Potential and distribution of transplanted hematopoietic stem cells in a nonablated mouse model. Blood. 89:4013-4020.

Nygren, J.M., and D. Bryder. 2008. A novel assay to trace proliferation history in vivo reveals that enhanced divisional kinetics accompany loss of hematopoietic stem cell self-renewal. PLoS One. 3:e3710. doi:10.1371/ journal.pone. 0003710

Nygren, J.M., S. Jovinge, M. Breitbach, P. Säwén, W. Röll, J. Hescheler, J. Taneera, B.K. Fleischmann, and S.E. Jacobsen. 2004. Bone marrowderived hematopoietic cells generate cardiomyocytes at a low frequency through cell fusion, but not transdifferentiation. Nat. Med. 10:494-501. doi: $10.1038 / \mathrm{nm} 1040$

Osawa, M., K. Hanada, H. Hamada, and H. Nakauchi. 1996. Long-term lymphohematopoietic reconstitution by a single CD34-low/negative hematopoietic stem cell. Science. 273:242-245. doi:10.1126/science .273 .5272 .242

Papayannopoulou, T., and D.T. Scadden. 2008. Stem-cell ecology and stem cells in motion. Blood. 111:3923-3930. doi:10.1182/blood-200708-078147

Plett, P.A., S.M. Frankovitz, and C.M. Orschell-Traycoff. 2002. In vivo trafficking, cell cycle activity, and engraftment potential of phenotypically defined primitive hematopoietic cells after transplantation into irradiated or nonirradiated recipients. Blood. 100:3545-3552. doi:10.1182/blood. V100.10.3545

Prockop, S.E., and H.T. Petrie. 2004. Regulation of thymus size by competition for stromal niches among early $\mathrm{T}$ cell progenitors. J. Immunol. 173:1604-1611

Quesenberry, P.J., H. Ramshaw, R.B. Crittenden, F.M. Stewart, S. Rao, S. Peters, P. Becker, P. Lowry, M. Blomberg, J. Reilly, et al. 1994. Engraftment of normal murine marrow into nonmyeloablated host mice. Blood Cells. 20:348-350.

Ramirez, P., M.P. Rettig, G.L. Uy, E. Deych, M.S. Holt, J.K. Ritchey, and J.F. DiPersio. 2009. BIO5192, a small molecule inhibitor of VLA-4, mobilizes hematopoietic stem and progenitor cells. Blood. 114:13401343. doi:10.1182/blood-2008-10-184721
Rao, S.S., S.O. Peters, R.B. Crittenden, F.M. Stewart, H.S. Ramshaw, and P.J. Quesenberry. 1997. Stem cell transplantation in the normal nonmyeloablated host: relationship between cell dose, schedule, and engraftment. Exp. Hematol. 25:114-121.

Robinson, S., R. van Os, T. Sheridan, and P. Mauch. 2000. Reduction of marrow hematopoietic progenitor and stem cell content is not sufficient for enhanced syngeneic engraftment. Stem Cells. 18:93-101. doi:10.1634/stemcells.18-2-93

Ron, Y., and J. Sprent. 1985. Prolonged survival in vivo of unprimed B cells responsive to a T-independent antigen. J. Exp. Med. 161:1581-1586. doi:10.1084/jem.161.6.1581

Rossi, D.J., D. Bryder, J.M. Zahn, H. Ahlenius, R. Sonu, A.J. Wagers, and I.L. Weissman. 2005. Cell intrinsic alterations underlie hematopoietic stem cell aging. Proc. Natl. Acad. Sci. USA. 102:9194-9199. doi:10.1073/pnas.0503280102

Rossi, D.J., J. Seita, A. Czechowicz, D. Bhattacharya, D. Bryder, and I.L. Weissman. 2007. Hematopoietic stem cell quiescence attenuates DNA damage response and permits DNA damage accumulation during aging. Cell Cycle. 6:2371-2376.

Samokhvalov, I.M., N.I. Samokhvalova, and S. Nishikawa. 2007. Cell tracing shows the contribution of the yolk sac to adult haematopoiesis. Nature. 446:1056-1061. doi:10.1038/nature05725

Saxe, D.F., S.S. Boggs, and D.R. Boggs. 1984. Transplantation of chromosomally marked syngeneic marrow cells into mice not subjected to hematopoietic stem cell depletion. Exp. Hematol. 12:277-283.

Schofield, R. 1978. The relationship between the spleen colony-forming cell and the haemopoietic stem cell. Blood Cells. 4:7-25.

Schwarz, B.A., and A. Bhandoola. 2004. Circulating hematopoietic progenitors with T lineage potential. Nat. Immunol. 5:953-960. doi:10.1038/ ni1101

Slavin, S., A. Nagler, E. Naparstek, Y. Kapelushnik, M. Aker, G. Cividalli, G. Varadi, M. Kirschbaum, A. Ackerstein, S. Samuel, et al. 1998 Nonmyeloablative stem cell transplantation and cell therapy as an alternative to conventional bone marrow transplantation with lethal cytoreduction for the treatment of malignant and nonmalignant hematologic diseases. Blood. 91:756-763.

Stewart, F.M., R.B. Crittenden, P.A. Lowry, S. Pearson-White, and P.J Quesenberry. 1993. Long-term engraftment of normal and post-5-fluorouracil murine marrow into normal nonmyeloablated mice. Blood. 81:2566-2571.

Stewart, F.M., S. Zhong, J. Wuu, C. Hsieh, S.K. Nilsson, and P.J. Quesenberry. 1998. Lymphohematopoietic engraftment in minimally myeloablated hosts. Blood. 91:3681-3687.

Sudo, K., H. Ema, Y. Morita, and H. Nakauchi. 2000. Age-associated characteristics of murine hematopoietic stem cells. J. Exp. Med. 192:12731280. doi:10.1084/jem.192.9.1273

Sugiyama, T., H. Kohara, M. Noda, and T. Nagasawa. 2006. Maintenance of the hematopoietic stem cell pool by CXCL12-CXCR 4 chemokine signaling in bone marrow stromal cell niches. Immunity. 25:977-988. doi:10.1016/j.immuni.2006.10.016

van Os, R., T.M. Sheridan, S. Robinson, D. Drukteinis, J.L. Ferrara, and P.M. Mauch. 2001. Immunogenicity of Ly5 (CD45)-antigens hampers long-term engraftment following minimal conditioning in a murine bone marrow transplantation model. Stem Cells. 19:80-87. doi:10.1634/stemcells.19-1-80

Visnjic, D., Z. Kalajzic, D.W. Rowe, V. Katavic, J. Lorenzo, and H.L. Aguila. 2004. Hematopoiesis is severely altered in mice with an induced osteoblast deficiency. Blood. 103:3258-3264. doi:10.1182/blood2003-11-4011

Wagers, A.J., R.I. Sherwood, J.L. Christensen, and I.L. Weissman. 2002. Little evidence for developmental plasticity of adult hematopoietic stem cells. Science. 297:2256-2259. doi:10.1126/science.1074807

Wiesmann, A., R.L. Phillips, M. Mojica, L.J. Pierce, A.E. Searles, G.J. Spangrude, and I. Lemischka. 2000. Expression of CD27 on murine hematopoietic stem and progenitor cells. Immunity. 12:193-199. doi:10.1016/S1074-7613(00)80172-7

Wilson, A., E. Laurenti, G. Oser, R.C. Van Der Wath, W. Blanco-Bose, M. Jaworski, S. Offner, C.F. Dunant, L. Eshkind, E. Bockamp, et al. 
2008. Hematopoietic stem cells reversibly switch from dormancy to self-renewal during homeostasis and repair. Cell. 135:1118-1129.

Wright, D.E., A.J. Wagers, A.P. Gulati, F.L. Johnson, and I.L. Weissman. 2001. Physiological migration of hematopoietic stem and progenitor cells. Science. 294:1933-1936. doi:10.1126/science.1064081

Wu, D.D., and A. Keating. 1993. Hematopoietic stem cells engraft in untreated transplant recipients. Exp. Hematol. 21:251-256.
Xu, H., B.G. Exner, P.M. Chilton, C. Schanie, and S.T. Ildstad. 2004. CD45 congenic bone marrow transplantation: evidence for $\mathrm{T}$ cell-mediated immunity. Stem Cells. 22:1039-1048. doi:10.1634/stemcells.22-6-1039

Zhang, J., C. Niu, L. Ye, H. Huang, X. He, W.G. Tong, J. Ross, J. Haug, T. Johnson, J.Q. Feng, et al. 2003. Identification of the haematopoietic stem cell niche and control of the niche size. Nature. 425:836-841. doi:10.1038/nature02041 